\title{
Research on safety evaluation of portal crane based on energy saving and environmental protection
}

\author{
Yaoting Tong ${ }^{1, *}$, Bozheng Wei ${ }^{2}$, Lixin Ren ${ }^{1}$, and Weiping Ouyang ${ }^{1}$ \\ ${ }^{1}$ Shanghai Institute of Special Equipment Inspection and Technical Research, Shanghai, 200062 \\ ${ }^{2}$ Shanghai Fengxian District Special Equipment Inspection Institute, Shanghai 201406
}

\begin{abstract}
Crane is an important equipment of national economic construction. Compared with the faulty crane, the crane with good performance has lower energy consumption and less pollution to the environment. In this paper, the analytic hierarchy process is used to evaluate the safety of portal crane, to help users find and deal with the existing problems of crane in time, and to play a positive role in the sustainable development of national economy.
\end{abstract}

\section{Introduction}

\subsection{Research Significance}

Portal crane brings convenience, quickness, flexibility and high efficiency to production. At the same time, accidents occur frequently due to the unsafe factors of the equipment itself, which brings losses to the national economy and ecological environment. In order to ensure the safe operation of the equipment, in addition to routine maintenance and maintenance, safety evaluation in the process of equipment use is an essential work ${ }^{[1]}$. We should not only consider the comprehensive performance of the equipment, but also consider the factors of structural safety, so as not to be forced to scrap in the service life of the equipment, so as to avoid economic waste. However, if the cost of the equipment is over considered and the equipment with potential safety hazards is put into use, it will cause accidents and increase energy consumption. Therefore, scientific and reasonable safety evaluation is very necessary.

\subsection{Safety analysis and research status of portal crane at home and abroad}

Chen zuqiang and Shi Gonghe used MSc fatigue to calculate the multi axial fatigue life of the structure, and analyzed the cracking causes of the metal structure of the portal crane end beam and horse leg ${ }^{[2]}$. According to the actual load situation, Fatemi-Society model was selected as the multi axis fatigue life analysis model, and the elastic-plastic finite element analysis was carried out with MSC fatigue. Fatigue is used to calculate the multi axial fatigue life of the structure to predict the fatigue life of the structure. The calculation results and practical application show that it can be applied to the fatigue life calculation of large portal crane structure.
For the hazard sources of large complete sets of equipment, SOLUZIONA and TRANSE LECTICA developed a set of reliability management software system based on hazard identification and risk assessment. The system can judge the external performance of the equipment through fuzzy comprehensive evaluation ${ }^{[3]}$, establish and analyze the root cause of failure, identify the failure hazard source, and realize quantitative analysis.

In the above studies at home and abroad, although experts and scholars have analyzed and explored the causes of the defects and hazards of portal crane, there is a lack of safety analysis and Research on the whole gantry crane, especially on the safety analysis method.

\subsection{The main content of this paper}

The damage caused by the accidents caused by uncertain factors during the service period of portal crane has attracted much attention. In this paper, according to the requirements of establishing safety evaluation system, the safety evaluation system of portal crane is constructed by using analytic hierarchy process. Through the analytic hierarchy process to establish the index system model, select the specific evaluation index and determine the evaluation value, adjust and determine the weight relationship between the projects. The evaluation value of each level is calculated by the mathematical method of fuzzy comprehensive evaluation, and the evaluation value of the whole crane is calculated, and the overall safety evaluation of the whole crane is made. The safety evaluation of an active portal crane is carried out by the above method. 


\section{Figures and tables}

\subsection{Analytic hierarchy process}

Analytic hierarchy process is a multi-criteria decisionmaking method, which combines qualitative and quantitative. It decomposes the elements related to decision-making problems into several levels, such as objectives, criteria and schemes, and carries out quantitative and qualitative analysis on this basis. The basic idea is: the decision-making problem is decomposed into different levels of structure, which is generally divided into general objective, sub-objective and evaluation criteria according to the order of alternatives. Then, by using the method of finding the eigenvector of judgment matrix ${ }^{[4]}$, the weight of each element of a certain level relative to a certain element of the previous level is reduced by using the method of weighted sum, and finally the evaluation of each scheme to the overall objective is obtained value.

Using AHP to determine the weight is divided into three steps: (1) establishing the hierarchical structure of the system; (2) constructing the comparative judgment matrix; (3) calculating the relative weight of each level and consistency test ${ }^{[5-6]}$.

\subsubsection{Hierarchical structure of the system}

Before using analytic hierarchy process to analyze problems, the model of analytic hierarchy process (AHP) requires the problem to be organized and hierarchical. The factors of each level have different attributes, which are decomposed from top to bottom. Many factors in the lower level belong to or have influence on the upper level, and the upper level is affected by the lower level factors. The top layer is the target layer, and generally there is only one factor. The bottom layer is often the object or scheme layer, and the middle is usually the criterion or indicator layer. When there are more than 9 selected indicators, they are decomposed into sub index layers. Before establishing a reasonable hierarchical structure, decision makers should have a comprehensive and in-depth understanding of relevant issues.

According to the composition characteristics of portal crane, its safety performance can be divided into four levels. The first level and the problem we need to solve is the risk assessment value of portal crane. The second level can be divided into the electrical system, mechanism and structure of equipment. The factors in the second level can be subdivided into slewing table status, crane boom status, A-frame status, pedestal status, luffing mechanism status, main hoist status, power loop status, slewing mechanism safety, control system status and control loop status. In the fourth level, the factors in the third level are subdivided into the lowest influencing factors that cannot be split again, for example, the luffing mechanism status can be subdivided into brake status, luffing motor status, coupling status, reducer status, pulley status, steel rope status and shaft, pin and key status (The safety evaluation structure of portal crane is shown in Fig. 1).

\subsubsection{Comparison judgment matrix}

Analytic hierarchy process (AHP) mainly constructs judgment matrix to judge the relative importance of each factor in each level, and introduces appropriate scale to express it by numerical value. The judgment matrix represents the comparison of the relative importance of the factors in this layer to those in the previous level. Judgment matrix is an important basis for the calculation of relative importance and the basic information of AHP.

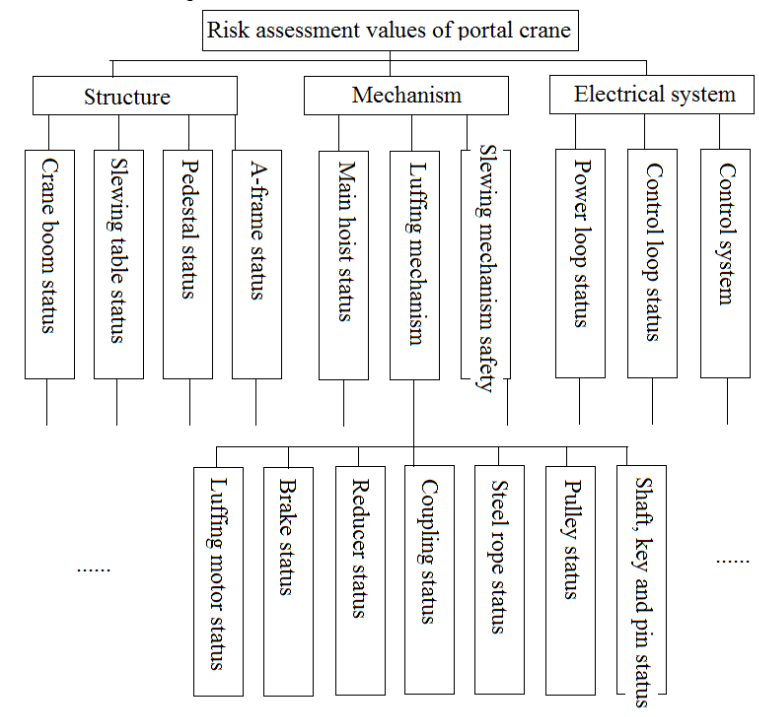

Fig. 1. The safety evaluation structure of portal crane

Then, if there are $\mathrm{n}$ elements, the pairwise comparison judgment matrix $A=\left(a_{i j}\right)_{n \times n}$ is constructed. Where $a_{i j}$ represents the importance of element $i$ and element $j$ relative to the target. The form of constructing judgment matrix is as follows:

$$
A=\left[\begin{array}{ccc}
a_{11} & \ldots & a_{1 n} \\
\vdots & a_{i j} & \vdots \\
a_{n 1} & \ldots & a_{n n}
\end{array}\right]
$$

In the analytic hierarchy process (AHP), the matrix of formula (1) $A$ is called positive and negative matrix. In order to make quantitative decision and judgment, the above-mentioned numerical comparison judgment matrix is formed, and the judgment is quantified by a certain ratio scaling method. A commonly used 1-9 scaling method ${ }^{[7]}$ is given below (as shown in Table 1).

Table 1. The scale of judgment matrix and its meaning.

\begin{tabular}{|c|c|c|}
\hline $\begin{array}{c}\text { Serial } \\
\text { number }\end{array}$ & Importance level & $\begin{array}{c}a_{i j} \\
\text { assignment }\end{array}$ \\
\hline 1 & $\begin{array}{c}\text { Element } i \text { and } j \text { are equally } \\
\text { important }\end{array}$ & 1 \\
\hline 2 & $\begin{array}{c}\text { Element } i \text { is slightly more } \\
\text { important than element } j\end{array}$ & 3 \\
\hline
\end{tabular}




\begin{tabular}{|c|c|c|}
\hline 3 & $\begin{array}{c}\text { Element } i \text { is obviously more } \\
\text { important than element } j\end{array}$ & 5 \\
\hline 4 & $\begin{array}{c}\text { Element } i \text { is remarkably more } \\
\text { important than element } j\end{array}$ & 7 \\
\hline 5 & $\begin{array}{c}\text { Element } i \text { is extremely more } \\
\text { important than element } j\end{array}$ & 9 \\
\hline 6 & $\begin{array}{c}\text { Element } i \text { is slightly less } \\
\text { important than element } j\end{array}$ & $1 / 3$ \\
\hline 7 & $\begin{array}{c}\text { Element } i \text { is obviously less } \\
\text { important than element } j\end{array}$ & $1 / 5$ \\
\hline 8 & $\begin{array}{c}\text { Element } i \text { is remarkably less } \\
\text { important than element } j\end{array}$ & $1 / 7$ \\
\hline 9 & $\begin{array}{c}\text { Element } i \text { is extremely less } \\
\text { important than element } j\end{array}$ & $1 / 9$ \\
\hline
\end{tabular}

The relative importance of each factor in the second layer of the evaluation structure chart relative to the first level factor $t$ is expressed in the scale of $1-9$, which can be expressed as the matrix shown in Table 2. The matrix shown in Table 2 can express the importance of the factors in a certain layer to the directly related factors of the upper level, so it is also called the comparison matrix. The maximum eigenvector of the matrix $\mathrm{T}$ can be calculated by using the sum product method, so as to obtain the importance coefficient of the second level for the target layer $\mathrm{T}$ is $\omega=(0.566,0.242,0.192)^{\mathrm{t}}$.

In the same way, the comparison matrix of the factors at the third level to the directly related factors at the second level and the factors at the fourth level to the corresponding directly related factors at the third level can also be obtained. The eigenvector of the comparison matrix can be obtained by calculation, the maximum eigenvectors of the comparison matrix of each factor in the third level are: $\omega 1=(0.386,0.204,0.197) \mathrm{t}$; $\omega 2=(0.174,0.723,0.103) \mathrm{t} ; \omega 3=(0.106,0.260,0.634) \mathrm{t}$.

Table 2. Comparison Matrix of Factors on the Second Level to the Target Level T for Portal Cranes.

\begin{tabular}{|c|c|c|c|}
\hline $\mathrm{T}$ & $\mathrm{A} 1$ & $\mathrm{~A} 2$ & $\mathrm{~A} 3$ \\
\hline $\mathrm{A} 1$ & 1 & 4 & 2 \\
\hline $\mathrm{A} 2$ & $1 / 3$ & 1 & 2 \\
\hline $\mathrm{A} 3$ & $1 / 5$ & $1 / 2$ & 1 \\
\hline
\end{tabular}

\subsubsection{Hierarchical single ranking and consistency checking}

Hierarchical single ranking refers to the calculation of the weight set of the relative importance of each element in the hierarchy and an element in the upper level. It is based on the data of comparative judgment matrix. The weight of the feature matrix is transformed into a twodimensional matrix. According to AHP method, when the random consistency ratio $\mathrm{CR}$ of each comparison matrix satisfies $C R<0.10$, the consistency verification of comparison matrix passes.

The maximum characteristic root $\lambda \max$ can be obtained as per Formula 2:

$$
\lambda_{\max }=\sum_{1}^{n} \frac{(A \omega)_{i}}{n \omega_{i}}(i=1,2, \ldots n)
$$

The consistency index (CI) of comparison index is shown in Formula 3:

$$
C I=\frac{\lambda_{\max }-n}{n-1}
$$

The random index RI (random index) of comparison matrix can be found through the order RI table (Table 3), then the random consistency ratio $\mathrm{CR}$ (consistency ratio) of comparison matrix is shown in Formula 4:

Table 3. Average random consistency index R.I.

\begin{tabular}{|c|c|c|c|c|c|}
\hline Order $\mathrm{n}$ & 1 & 2 & 3 & 4 & 5 \\
\hline R.I. & 0 & 0 & 0.52 & 0.89 & 1.12 \\
\hline Order $\mathrm{n}$ & 6 & 7 & 8 & 9 & 10 \\
\hline R.I. & 1.26 & 1.36 & 1.41 & 1.46 & 1.49 \\
\hline R.I. & 11 & 12 & 13 & 14 & 15 \\
\hline Order $\mathrm{n}$ & 1.52 & 1.54 & 1.56 & 1.58 & \\
$C R$ & $=\frac{C I}{R I}$
\end{tabular}

After calculation, the maximum eigenvalue of matrix $\mathrm{t}$ is $\lambda \max =3.024, \mathrm{CI}=0.012$, and the third-order matrix $\mathrm{RI}=0.58$, then $\mathrm{CR}$ can be calculated to obtain $\mathrm{CR}=0.02$ $<0.10$, so matrix $\mathrm{T}$ passes the consistency test.

In the same way, the consistency of comparison matrices of the third level to the second level and the fourth level to the third level is verified respectively. Through calculation, the CR values of each comparison matrix are all less than 0.10 , so the AHP hierarchy safety evaluation method based on expert experience and data statistics is available for portal crane.

\subsection{Safety performance result evaluation value $D$ and range definition}

By calculating the maximum eigenvector of the comparison matrix, the coefficients of the safety evaluation method for portal crane based on AHP method can be determined. After the equipment is inspected by the inspectors, the factors of the gantry crane can be scored according to the inspection results (each state is expressed according to the percentage system, and the best state is 100 points). After normalizing each score, the corresponding real-time status score I of each evaluation index is obtained. Then, the safety performance evaluation value $\mathrm{D}$ of the equipment can be calculated according to formula 5 . 
According to the $\mathrm{D}$ value, the real-time security status and risk degree of the device can be obtained.

$$
D=\sum_{1}^{n} \omega_{i} \times I_{i}(i=1,2, \ldots 49,0 \leq D \leq 1)
$$

According to the characteristics of gantry crane, the safety status corresponding to different value range of $\mathrm{D}$ value and the measures to be taken are defined by experts (as shown in Table 4).

Table 4. Safety Status and Necessary Corrective Actions Corresponding to Different Values of D

\begin{tabular}{|c|c|c|}
\hline $\begin{array}{c}\text { Range of value } \\
\mathrm{D}\end{array}$ & Safety status & Necessary measure \\
\hline $\mathrm{D}<0.125$ & $\begin{array}{c}\text { Extreme } \\
\text { risk }\end{array}$ & $\begin{array}{c}\text { The crane should be } \\
\text { scrapped }\end{array}$ \\
\hline $0.125 \leq \mathrm{D}<0.25$ & $\begin{array}{c}\text { Remarkable } \\
\text { risk }\end{array}$ & $\begin{array}{c}\text { Shut down for } \\
\text { overhaul }\end{array}$ \\
\hline $0.25 \leq \mathrm{D}<0.375$ & High risk & $\begin{array}{c}\text { Stop using and repair } \\
\text { related parts }\end{array}$ \\
\hline $0.375 \leq \mathrm{D}<0.5$ & $\begin{array}{c}\text { Obvious } \\
\text { risk }\end{array}$ & $\begin{array}{c}\text { The crane has an } \\
\text { obviously fault, so } \\
\text { the relevant repair } \\
\text { plan should be } \\
\text { formulated to speed } \\
\text { up the repair }\end{array}$ \\
\hline $0.5 \leq \mathrm{D}<0.625$ & Moderate \\
risk & $\begin{array}{c}\text { The failure of the } \\
\text { crane is serious, so it } \\
\text { should be considered } \\
\text { to formulate relevant } \\
\text { repair plan and repair } \\
\text { it timely }\end{array}$ \\
\hline $0.625 \leq \mathrm{D}<0.75$ & Low risk & $\begin{array}{c}\text { The crane runs } \\
\text { faulty, it is necessary } \\
\text { to check the fault } \\
\text { point regularly and } \\
\text { repair the damaged } \\
\text { parts }\end{array}$ \\
\hline Slight risk & $\begin{array}{c}\text { The crane runs } \\
\text { normally, but } \\
\text { inspection should be } \\
\text { strengthened }\end{array}$ \\
\hline The crane runs well \\
\hline
\end{tabular}

\section{Practical Application}

In a port in Shanghai, an in-service portal crane was evaluated by AHP method. After the overall inspection of the equipment, all factors in the fourth layer shown in the evaluation structure model diagram (Figure 1) were scored (as shown in Table 5), and the logarithm was normalized. According to formula 5, the safety performance evaluation value $\mathrm{D}$ of the equipment was calculated to be 0.782 .

According to table 4, the real-time status of this equipment is slight risk, which indicates that the overall performance of the equipment is relatively good, and it is enough to strengthen the inspection of the equipment in use.
Table 5. Scores of Safety Performance Assessment for Portal Cranes

\begin{tabular}{|c|c|c|c|}
\hline Item & Score & Item & Score \\
\hline$\ldots$ & $\ldots$ & $\begin{array}{c}\text { Steel rope } \\
\text { status }\end{array}$ & 75 \\
\hline $\begin{array}{c}\text { Luffing motor } \\
\text { status }\end{array}$ & 80 & $\begin{array}{c}\text { Pulley } \\
\text { status }\end{array}$ & 76 \\
\hline Brake status & 83 & $\begin{array}{c}\text { Shaft, key } \\
\text { and pin } \\
\text { status }\end{array}$ & 71 \\
\hline Reducer status & 65 & $\ldots$ & $\ldots$ \\
\hline Coupling status & 60 & & \\
\hline
\end{tabular}

\section{Conclusion}

In this paper, the portal crane as the research object, on the basis of the relevant theoretical knowledge of safety evaluation, through the analytic hierarchy process of the portal crane safety evaluation method is studied, the process of safety evaluation of the whole gantry crane is given, and a scientific and reasonable safety evaluation system is established for the portal crane, through the specific measurement and calculation and analysis, the safety index of crane is obtained as the basis for the conclusion of equipment scrap or maintenance. At the same time, it can find out the parts with faults or hidden dangers, so as to guide the safety management door of the crane, formulate the corresponding inspection system, determine the key inspection parts and inspection cycle, and reasonably formulate and arrange the maintenance plan.

\section{References}

1. Liu Shuangyue. (2010) Safety evaluation. Metallurgical Industry Press, Beijing.

2. Chen zuqiang, Shi Gonghe,et al. (2010) Multiaxial fatigue life analysis of portal crane end beam and horse leg structure. Computer aided engineering, 02:83-86.

3. Xu Xueyan. (2011) Research and application of fuzzy comprehensive evaluation model, Chengdu.

4. Chu min. (2005) construction of judgment matrix in analytic hierarchy process, Nanjing.

5. Tian Zhiyou, Wang Huanchen, et al. (2004) Consistency test and improvement of possible satisfaction and judgment matrix. System engineering theory and practice, 12:94-99.

6. Dong Shuai, Wang Yongji, et al. (2011) Research on consistency adjustment method of index scale judgment matrix. Computing technology and automation, 04:1-4.

7. Jiang Wenqi. (2011) Sensitivity of dimensionless method to attribute weight and scheme order preservation. Systems engineering and electronic technology, 12:2520-2523. 